\title{
Can a Developing Country Support the Welfare Needs of Children Affected by AIDS? Considering the Issues in Zambia
}

\author{
Malcolm F. McPherson`
}

\begin{abstract}
1 Introduction
In this debate, I am the Grinch. I argue that developing countries (especially those with highprevalence generalised AIDS epidemics) cannot support the welfare needs of children affected by AIDS. There are two reasons. First, countries that attempt this task risk undermining their capacity for economic growth. Growth failure will affect their ability to sustain any assistance they may already be providing to children affected by AIDS. Second, these countries also face other development challenges. Assisting children and adults who are hungry, illiterate, ill, displaced, or otherwise destitute is no less compelling - economically or financially - than supporting children affected by AIDS.
\end{abstract}

My arguments reflect concerns about efficiency and (horizontal) equity. Neither principle excludes providing some (modest) assistance to children affected by AIDS as part of broader support to the disadvantaged. That support, however, can only be sustained if countries avoid distorting their economies by giving exaggerated attention to specific problems.

The article is organised as follows. It first examines why poor countries should focus on efficiency and equity. It then argues that no developing country should devote all the resources it can muster to children affected by AIDS (or any other single development issue). Section three examines the consequences of having the donors provide the necessary resources. Data from Zambia are used to anchor the arguments but the conclusions hold equally well throughout sub-Saharan Africa.

\author{
2 Why are efficiency and (horizontal) equity \\ relevant to this debate? \\ Efficiency is fundamental in economics. To economise \\ is to be efficient (i.e. avoid waste). Allocating large \\ amounts of resources to meet the needs of one \\ specific group is inefficient and reallocating some of \\ those resources to other purposes would raise \\ national income and welfare. Being poor, developing \\ countries have the least ability to sustain waste. \\ Government policies that promote efficiency boost \\ the rate of economic growth, raising the welfare of \\ the whole population. Public activities that are \\ inefficient and government policies that generate \\ waste have the opposite effect.
}

Horizontal equity involves the equal treatment of members of any society who are in (roughly) similar circumstances. This principle highlights the question: if a developing country decides to fully support the welfare needs of children affected by AIDS, what responsibility does it have for the needs of other citizens who are hungry, poorly educated, ill, displaced, and/or marginalised? Who decides and why it is essential to respond to the deprivation of one group and not others? Emphasising horizontal equity encourages activities that, within the limits of the nation's capabilities, address deprivation irrespective of its source.

Resolving issues related to efficiency and equity is never easy. Decision-makers differ on the relative importance of these and other social, political and economic issues. Yet, since all resources are scarce, how decision-makers allocate resources always has 
efficiency and equity effects. Pretending otherwise does not help. ${ }^{1}$ It is the same even when the international community provides the resources. The only change is the nature of the choices. ${ }^{2}$

Ample evidence is available. Consider the development trajectories in Asia and Africa over the last five decades. In the former, rapid economic growth and social development lifted several hundred million people out of poverty. In the latter, the lack of these has driven as many as $\mathbf{2 0 0}$ million people deeper into poverty. Much of the difference in performance between the two regions can be related to the choices made by the various governments as they mobilised and allocated their resources.

The example of Zambia illustrates what is involved in supporting the welfare needs of children affected by AIDS. It has a high-prevalence generalised AIDS epidemic. It is receiving extraordinary levels of assistance from the US President's Emergency Plan for AIDS Relief (PEPFAR), the Global Fund, the World Bank, UNAIDS, numerous NGOs and several bilateral assistance agencies. Data are presented for 2005, when Zambia's population was 11.5 million, growing at 2.2 per cent per annum. The HIV prevalence among adults was 17 per cent, an estimated 98,000 people died of AIDS, the number of children and adults living with HIV was around 1.1 million, and the number of AIDS orphans was estimated to be $710,000{ }^{3}$ Forty-six per cent of the population was aged $0-15$ years. ${ }^{4}$ The total value of goods and services produced (i.e. the country's GDP) was US\$6.93 billion. ${ }^{5}$ Average per capita income was around US\$600 or roughly US $\$ 900$ when adjusted for international purchasing power (PPP). Due to the skewed distribution of national income, ${ }^{6} 64$ per cent of Zambia's population had expenditure below the PPP-adjusted benchmark of ' $\$ 1$ a day' and 87 per cent below \$2/day. During 2005, GDP grew by 4.3 per cent.

Can Zambia support the welfare needs of children affected by AIDS?? The majority of Zambian children are affected by AIDS and to set a number, it will be assumed here that 3 million children, slightly below 60 per cent, are affected by AIDS. These children need primary healthcare, education and social welfare. What level of expenditure would support those needs? Cost estimates vary from several hundred dollars to a few thousand per child per year. One benchmark (again to set a number) is the poverty line of $\$ 2 /$ day, equivalent to $\$ 2.65 /$ day in 2005 prices, or US\$1,060 per year. ${ }^{8}$ Using the equivalent of ' $\$ 1$ a day' would halve the cost. This, however, is the international limit for 'absolute poverty' and it hardly seems consistent to argue that governments are meeting children's welfare needs if the support provided keeps them in absolute poverty. The estimates below use US\$1,000 per child per year or US\$3 billion in total.

In 2005 , this US\$3 billion, was equivalent to 43 per cent of GDP, 51 per cent of total (public and private) consumption expenditure, 163 per cent of total government expenditure, 145 per cent of total imports of goods and services, and 620 per cent of international grants provided to the government. This is a large amount, both absolutely and relatively.

\section{Why not devote all available resources to children affected by AIDS?}

Suppose governments in countries with generalised AIDS epidemics and their donors acknowledge that although efficiency and equity are important, the welfare needs of children affected by AIDS have to be met? Why should anyone object? Two reasons stand out.

First, no developing country in such circumstances could raise the required resources. As mentioned, in 2005, Zambia would have required at least

US\$3 billion to ensure that 3 million children were supported at a level that is close to (but below) the international poverty standard of \$2/day. In that year, the government budget was equivalent to 26 per cent of GDP. With Zambia having run a budget deficit continuously since $1974,{ }^{9}$ and thereby accumulated unserviceable debts, ${ }^{10}$ the required resources will have to come entirely from the international community. Furthermore, roughly the same amount of US\$3 billion (adjusted for inflation) will need to be spent in each subsequent year while the epidemic persists and children continue to be affected by AIDS. Zambia lacks financial capacity (whether measured as fiscal space or creditworthiness) to sustain this.

Second, by deciding to support children affected by AIDS, the government would be unable to also meet other pressing needs, exacerbating illiteracy, food insecurity, inadequate infrastructure, ill-health, unemployment and rural poverty (among others). Thus, even if no one objected to the policy of fully 
supporting children affected by AIDS, it could not succeed. The distortions created by neglecting other dimensions of deprivation would increase poverty and intensify marginalisation. Short of war, persistent economic distortions are the most potent incomereducing and wealth-destroying mechanisms yet devised. Children affected by AIDS would not enjoy sustained benefits if the activities that support them undercut the economy

4 What if others provide the required resources? Suppose the international community provide all the resources (commodities, finance, technical assistance) required for children affected by AIDS? There are two difficulties. First, the resource flows required are significantly larger than any the international community has ever attempted to provide to a single country. The US\$3 billion for Zambia in 2005 noted above is more than six times greater than total cash grants received in that year. Second, even if the international community were to provide the necessary finance, the local resources required - human and physical capital, institutional and organisational capacities, knowledge, and transparent governance structures - could not be scaled-up commensurately."

A lesson that poor countries (especially those in Africa) can learn from Asian development experience is that knowing when to refuse foreign aid is often (far) more important for a country's efforts to sustain economic growth and development than agreeing to accept it.

Two issues are involved. The first is the short-term economic impacts of the additional expenditure. The second is the dynamic effects of attempting to maintain that resource injection for the foreseeable future. On both counts, Zambia lacks the capacity to sustain the effort. The economy is seriously overstretched. Years of budget deficits, and weak (and often inappropriate) financial, monetary and exchange rate management produced chronically high rates of inflation, undercut the economy's capacity for rapid economic growth, generated acute aid dependence, and created major imbalances in the structure of trade and the balance of payments. Economic performance has been poor. For example, paid (i.e. formal sector) employment has declined over most of the last decade, and the general population has limited education, poor health and is food insecure.

What would be the dynamic consequences of the injection of this level of resources into the Zambian economy? At least five economic effects are likely. First, inflation would accelerate. With the economy already having difficulty absorbing existing foreign assistance and the government running a budget deficit, additional assistance would boost the money supply, raising the rate of inflation. Second, the balance of payments would deteriorate. The resource inflows would significantly further appreciate the real exchange rate. This would accentuate Dutch disease, the effects of which (low economic growth,

increased international debt, rapid growth of imports, sluggish exports) Zambians have long experienced. Third, the additional expenditure would crowd out private sector activity. Wage inflation accompanying the increased demand for the limited supply of skilled professionals (teachers, nurses, managers, administrators, childcare specialists) to provide for children affected by AIDS would raise unit labour costs beyond the levels at which the private sector could remain competitive. Fourth, the economy would become significantly more aid dependent than at present and remain that way for the foreseeable future. Finally, the rate of urbanisation would accelerate. The overvalued real exchange rate and higher inflation would accentuate rural poverty forcing more people to migrate to the cities. Rural blight and food insecurity would intensify.

Notwithstanding post-2005 increases in copper prices and the subsequent expansion of mine output, the country's economic prospects remain far from buoyant. The dramatically improved outlook for mining exports has not boosted economic growth commensurately, nor has the improved financial outlook encouraged the government to reduce its budget and balance of payments deficits.12 The implication is that Zambia cannot afford to support the welfare needs of children affected by AIDS even if the effort were fully funded by the international community.

Cutting the number of children eligible for support to 1.5 million, halving the level of assistance provided each child, or even limiting the support to the 710,000 AIDS orphans would not change that conclusion. The economy's limited resource base and budget and balance of payments deficits do not provide the scope for large additional outlays whatever their source.

This outcome is not a legacy of colonialism. Zambia gained independence in 1964 as the third richest 
country in Africa with minimal levels of external debt, large budget and balance of payments surpluses, and a per capita income that was 40 per cent higher than that of South Korea. ${ }^{13}$ It is also not the result of globalisation. The policy changes announced by the Zambian government at Matero Hall (1968), Mulungushi Rock (1969), and as part of the Watershed Speech (1975), defined a trajectory specifically designed to insulate the economy from international influences. That approach worked only too well, progressively impoverishing the majority of Zambians by excluding them from the benefits of the expansion in world trade that, among other things, helped lift most of Asia and Latin America out of poverty.

Many of Zambia's difficulties can be traced to a pattern of partial and failed economic restructuring and policy-induced distortions that have persisted since the energy and food crises and the collapse of copper prices in the 1970s. Nothing has changed in the government's present approach to economic management to suggest this pattern has been abandoned.

\section{But, what if ...?}

How could Zambia and its donors respond to the welfare needs of children affected by AIDS? A constructive response would begin with the recognition that the main short-term challenge in Zambia is to provide security (food, healthcare and shelter) for the affected children while creating conditions which can provide those children with the opportunity for an expansive future. For this to materialise, Zambia needs to restructure its policies and activities so as to achieve rapid sustained economic growth. ${ }^{14}$ That would require taking full advantage of the country's assets (agriculture, mining, tourism, water resources) and drawing as many members of the country's labour force as possible into productive employment. Success would require the government to shift from its current focus on the welfare of the roughly 400,000 , primarily urbanbased, paid workers and promote policies that explicitly support the activities and occupations of poorer members of society - farmers, the informally employed and small-scale entrepreneurs.

What would such a change in emphasis do for children affected by AIDS? It would not provide resources to fully support their welfare needs. However, it would help boost the agriculture sector and rural and peri-urban economies, making Zambia less subject to food insecurity. It would also begin to generate employment, especially among those with few skills. That would expand their range of economic opportunities and encourage higher private spending on activities that enhance welfare - housing, health and education. The change would also allow Zambia to rationalise its relationship with the international community so that its economic and social policies could begin to fully reflect local priorities and not necessarily those that periodically emerge from Washington, Brussels, Paris and London. ${ }^{15}$ If implemented and sustained, the suggested restructuring would provide the government with the potential to expand its support for children affected by AIDS and to the many others in Zambia who are hungry, illiterate and otherwise deprived.

\section{Concluding observations}

This analysis of the Zambian case highlights three points. First, given its present and prospective economic performance, Zambia lacks the capacity to support the welfare needs of children affected by AIDS. The estimated cost is well beyond anything the Zambian economy could currently afford, or sustain. ${ }^{16}$ Second, the country cannot begin to create that capacity until improved economic management generates and sustains high rates of economic growth. Third, if constructively supported by the international community, the government could begin supplying some of the welfare needs of children affected by AIDS along with the welfare needs of other groups who are poor and deprived. This would require a substantive restructuring of the government policies and priorities (as reflected in the budget), including major reductions in non-welfarerelated expenditures.

Emphasising efficiency reminds developing countries intent on rapidly reducing poverty of the need for policies and programmes that induce the public and private sectors to use all available resources in ways that yield the highest (risk-adjusted) returns. Horizontal equity requires that all citizens (children, youth and adults) in similar circumstances be treated similarly.

How, critics will ask, can I emphasise efficiency and equity when the weight of opinion in the AIDS community is that the welfare needs of children affected by AIDS are so overwhelmingly compelling that governments and donors must meet them? Why do I refuse to accept that politics and interest group 
pressure trump issues of efficiency and equity? My position is that without attention to efficiency and equity and the restrictions they impose on the choices of governments and donors alike, the economic growth required to sustain any form of support for children affected by AIDS will not materialise.

With so few resources available and so few opportunities to obtain more (except through rapid sustained economic growth), developing countries lack the capacities to meet the welfare needs of children affected by AIDS. ${ }^{17}$ Those countries, however, cannot fully meet the welfare needs of all their citizens who are deprived. ${ }^{18}$ This is the unfortunate consequence of being poor. Acting as

\section{Notes}

1 Not deciding is not an option. As Lindholm (1959) noted, when decision-makers dither, the system 'grinds out' an outcome, often a poor one.

2 Articles by ActionAid and the Center for Global Development (www.actionaidusa.org/ imf_africa.php and www.cgdev.org/doc/ IMF/IMF_Report.pdf) criticise the International Monetary Fund (IMF) for what is seen as its uncompromising attitude to efforts by developing countries to increase the resources allocated to 'social spending'. The IMF defended itself (www.imf.org). Yet, making the IMF (or any other entity) the villain does not alter the fact that developing countries have too few resources to support all the social expenditures that local and external advocacy groups believe should be made.

3 The data come from UNAIDS (2005); USA.gov (2007); Dzekedzeke and Fylkesnes (2006).

4 World Bank World Development Indicators 2007, Table 2.1.

5 The data are from the International Monetary Fund (IMF 2006). The World Development Indicators (World Bank 2007, Table 4.2) report a higher GDP - US\$7.3 billion, with an implied average exchange rate of $\mathrm{K} 4,420$ to the US dollar.

6 The Gini coefficient for 2004 was 0.51. The highest 20 per cent of individuals received 55 per cent of income while the lowest quintile had 3.6 per cent (World Bank 2007, Table 2.7).

7 These are children '.. who are living with HIV or AIDS, those in a family with a member who is living with HIV or AIDS, and also children affected by the strains that AIDS places on communities and services'. though one misfortune can be remedied without creating others is not a solution.

The welfare needs of children affected by AIDS and of others who are disadvantaged will be met in developing countries with generalised AIDS epidemics through local efforts that improve economic performance and promote social development. The international community - donors, advocates, well-wishers - can assist if they complement local efforts. Adding more aid when existing resources are being used inefficiently and inequitably is a recipe for continued deprivation, not only for children affected by AIDS but for everyone else who is poor and deprived.

8 This was derived by adjusting the standard of $\$ 2.15 /$ day in 1993 prices to 2005 prices. The price data were taken from the United States Department of Labor, Bureau of Labor Statistics website (accessed 16 August 2007).

9 Most of these deficits have been large. For example, from 1998 to 2004 the annual budget deficit before grants averaged 12.7 per cent of GDP. After grants, the deficit averaged 6 per cent of GDP.

10 Since the early 1990s, Zambia has had billions of dollars of its external debt rescheduled, written off, written down, or restructured. Its external debt at the end of 2004 was US\$7.08 billion.

11 A widely held view among development specialists (e.g. Jeffrey Sachs' End of Poverty, 2005 and the United Nations Millennium Project's Investing in Development, 2005) is that scaling-up is relatively easy or, if difficulties arise, a matter of political will, or better governance. In reality, scaling-up has often been the most perplexing development challenge faced by developing countries. Indeed, one reason why African countries continue to have such low per capita incomes has been their general inability to scale up the host of activities that have first been tested/proved at the local level (McPherson 2003).

12 IMF 2006, January, Tables 3,4, pp34-5.

13 South Korea's GDP in 2005 was approximately US\$788 billion (World Bank 2007, Table 4.2).

14 A programme for reforming Zambia's economy is outlined in Hill and McPherson (2004: Chs 15, 17).

15 McPherson in Hill and McPherson (2004: Ch. 14) proposed an 'aid exit' strategy for Zambia as a 
means of helping end the country's acute aid dependence.

16 If the analysis is applied to sub-Saharan Africa as a whole, the same conclusion emerges. With GDP in 2005 of US\$662 billion and 332 million children aged $0-15$, the cost of supporting the welfare needs of (say) 30 per cent of those children at the international standard of \$2/day would be roughly US\$100 billion per year. Since total government recurrent expenditure in SSA in 2005 was US\$120 billion (18 per cent of GDP), this requirement, like the equivalent calculation for Zambia, is infeasible.

\section{References}

Dzekedzeke, K. and Fylkesnes, K. (2006) 'Reducing Uncertainties in Global HIV Prevalence Estimates: the Case of Zambia', British Public Health 83.6: April

Epstein, H. (2007) The Invisible Cure: Africa, the West, and the Fight Against AIDS, New York: Farrer, Straux and Giroux

Hill, C.B. and McPherson M.F. (2004) Promoting and Sustaining Economic Reform in Zambia, Cambridge MA: Harvard University Press

IMF (2006) 'Zambia: 2005 Article IV Consultation, Third Review Under the Three-Year Arrangement Under the Poverty Reduction and Growth Facility, Request for Waiver and Modification of Performance Criterion, and Financing Assurances Review - Staff Report; Public Information Notice and Press Release on the Executive Board Discussion; and Statement by the Executive Director for Zambia', International Monetary Fund Country Staff Report 06/39, January

Kristof, N. (2007) 'Wretched of the Earth', The New York Review of Books 54.9: 34-6

Lindholm, C.E. (1959) 'The Science of Muddling Through', Public Administration Review 19, Spring: 79-88
17 It requires a heart of stone not to be moved by the suffering caused by HIV/AIDS and the courage of individuals such as Nkosi Johnson (Wooten 2004) and whole communities (Epstein 2007: esp. Chs 8, 13). The debate here is not whether individual or a few children can be helped but all children who are affected by AIDS.

18 Nicholas Kristof's characterisation of the deepest tragedy wrought by poverty is that it forces individuals to make impossible (Hobson's) choices (Kristof 2007) - which child to educate, which child to put under a bed net at night, which family member to give medical attention, and so on.

McPherson, M.F. (2003) Scaling Up of HIV/AIDS Activities: A Critique, Center for Business and Government, John F. Kennedy School of Government, Harvard University, 30 April

Sachs, J.D. (2005) The End of Poverty: Economic Possibilities of Our Time, New York: Penguin

UNAIDS (Joint United Nations Programme on HIV/ AIDS) (2005) Fact Sheet Sub-Saharan Africa, UNAIDS and World Health Organization, UNAIDS Epidemic Update 2005, 21 November

United Nations (2005) Investing in Development: A Practical Plan to Achieve the Millennium Development Goals, New York: UN Millennium Project

USA.gov (2007) The President's Emergency Plan for AIDS Relief 2007 Country Profile: Zambia, www.USA.gov (accessed 14 August 2007)

Wooten, J. (2004) We are all the Same: A Story of a Boy's Courage and a Mother's Love, London: Penguin Books

World Bank (2007) World Development Indicators 2007, Washington DC: World Bank 